\title{
STUDY OF FLUIDIZED BED STEAM GASIFICATION OF CHAR BY THERMOGRAVIMETRICALLY OBTAINED KINETICS
}

\author{
ISAO MATSUI, DAIZO KUNII AND TAKEHIKO FURUSAWA \\ Department of Chemical Engineering, University of Tokyo, Bunkyo-ku, Tokyo 113
}

Key Words: Fluidized Bed, Gasification, Gasifier, Kinetics, Coal, Char, Steam, Thermogravimetry

\begin{abstract}
Gasification of coal-derived char by steam was carried out in a fluidized-bed reactor with a continuous feed and discharge of solids over a temperature range of 1096 to $1311 \mathrm{~K}$ at atmospheric pressure. Calculation based on the bubbling bed model and kinetic information obtained by thermogravimetric analysis explained the experimentally obtained conversions of both outgoing steam and char.
\end{abstract}

\section{Introduction}

A number of investigations of coal gasification kinetics have been conducted by use of thermogravimetric analysis, fixed-bed and fluidized-bed reactors. Dutta et al. ${ }^{5)}$ reviewed previously reported reaction rates and mentioned that some of the wide variation in reported values of activation energy could be attributed to not only the coal rank but also the reactor type used. May et al. ${ }^{10)}$ studied the kinetics of coal char gasification by use of fixed bed and fluidized bed and found that the difference in observed reaction rates could be interpreted by assuming the gas flow within the bed to be completely mixed. Squires ${ }^{13)}$ analyzed the data obtained by May ${ }^{10)}$ and suggested that the intensive solid circulation between the oxidizing atmosphere and the reducing atmosphere in a fluidized-bed gasifier might increase the reactivity of the coal surface and that this effect might be more clearly observed as the reaction temperature increases.

Thermogravimetric analysis can provide precise data in a well-defined gas atmosphere. However, a much slower heating rate of the sample might result in a significant difference in reaction rate. Burham ${ }^{3)}$ studied the gasification rate of oil shale by steam and carbon dioxide. A fluidized bed provided a larger rate than did a thermogravimetric apparatus. The discrepancy was explained by difference in pore structure. The smaller gasification rate obtained in the thermogravimetric apparatus was attributed to the smaller pore surface area caused by $\operatorname{tar}$ deposit, which is enhanced by reducing heating rate. Bjerle $e t$ al., ${ }^{1,2)}$ however, obtained a contrary result that the thermogravimetric apparatus provided a larger rate than did

Received May 11, 1984. Correspondence concerning this article should be addressed to T. Furusawa. 1. Matsui is now with Toshiba Corporation, Kawasaki 210. the fluidized bed. Thus it is likely that some of the wide variation in reported kinetic data is due to difficulties which arise in carrying out complete and quantitative evaluations of physical as well as chemical factors which affect the rate.

Thus it might be of practical concern whether the kinetic data obtained by thermogravimetric analysis could be used for design of a fluidized-bed gasifier. A number of investigations regarding gasifier analysis have been conducted, but only a limited number of analyses have been carried out by use of kinetic data obtained for the same char or coal as used in the gasifier analysis. Takeda et al. ${ }^{14,15)}$ studied the continuous fluidized-bed gasification system by use of the kinetic obtained by a smaller batch fluidized-bed reactor. However, the analysis was limited to a simplified fluidized bed modelling, based upon complete mixing of both gas and solid phases. Newby ${ }^{11)}$ reported a pioneering approach which analyzes sulphur dioxide retention in fluidized-bed combustion of coal by utilizing thermogravimetrically obtained kinetics. Argonne National Laboratory developed a similar approach for the evaluation of limestone utilization in a fluidized-bed combustor. ${ }^{6)}$

The present authors investigated the fluidized-bed steam gasification of char by utilizing a simple power law kinetic expression which did not contain the retardation terms of either reactant or products. ${ }^{9)} \mathrm{A}$ significantly large effective bubble diameter was required to explain the results. The first purpose of the present investigation was to carry out a detailed kinetic study of steam gasification of char by use of thermogravimetric analysis and to analyze the performance of a fluidized-bed gasifier by utilizing the kinetics obtained and a fluidized-bed model. The second objective was to explore the validity of the extrapolated rate for the analysis of fluidized-bed 
gasification at higher temperature, where the effects of solid circulation between the oxidizing zone and the reducing zone on reactivity was suggested. ${ }^{12,13)}$ The previously developed calculation procedure ${ }^{8)}$ based on the modified bubbling-bed model, which can predict conversions of both solid and gas phases for the reaction of nonlinear kinetics, was used for the present simulation of fluidized-bed gasification. Details of the numerical procedure will be found elsewhere. ${ }^{8)}$

\section{Thermogravimetric Analysis for Reaction Kinetics}

\subsection{Experimental}

Samples The char used for this investigation was obtained by carbonizing Taiheiyo non-caking subbituminous coal at $873 \mathrm{~K}$. The physical properties and analytical results of the char are shown in Table 1.

Apparatus All the experiments were conducted under isothermal conditions and at atmospheric pressure. The thermogravimetric apparatus consisted of a standard Shimadzu TG 31 microbalance, together with an external electric furnace section. The electric furnace was controlled by a conventional PID controller to attain both constant heating rate and constant reaction temperature. The reaction temperature was measured by a sheathed chromel-alumel thermocouple placed $5 \mathrm{~mm}$ below the sample basket. It was confirmed that the difference of temperature between the measuring point and the reacting particles was negligibly small.

A sample basket ( $20 \mathrm{~mm}$ i.d. and $10 \mathrm{~mm}$ in height) was made of 42-mesh platinum gauze. Several runs were performed also by using a quartz basket of the same size. In preliminary experiments, no appreciable effects of the type of sample basket on the rate obtained were observed. Char samples of particle sizes 297 to $710 \mu \mathrm{m}$ were placed in the basket to form a single layer, so that mass-transfer resistance through particle layers could be neglected.

Steam vapor was prepared by introducing nitrogen into the water vessel, the temperature of which was controlled by a constant-temperature bath. Concentration of steam was controlled by changing the temperature of the bath. All flow rates of nitrogen, hydrogen or carbon monoxide were adjusted at the desired level by soap film flowmeter.

Procedure The char sample was placed in the basket and the reactor was initially heated to about $423 \mathrm{~K}$. After the weight change due to the release of moisture was completed, the heating of the reactor was then conducted to the desired reaction temperature at a rate of $20 \mathrm{~K} / \mathrm{min}$ in the flowing nitrogen. When the desired temperature was attained, the sample was kept in a nitrogen atmosphere for more than $20 \mathrm{~min}$, until no weight change due to pyrolysis was detected by visual observation. Then the reactant gas was introduced into the reacting zone and the weight
Table 1. Properties of char employed

\begin{tabular}{|c|c|c|c|}
\hline Particle density & {$\left[\mathrm{kg} / \mathrm{m}^{3}\right]$} & & 1100 \\
\hline Bulk density & {$\left[\mathrm{kg} / \mathrm{m}^{3}\right]$} & & 710 \\
\hline Size & {$[\mu \mathrm{m}]$} & & $500 \sim 590$ \\
\hline $\begin{array}{l}\text { Minimum fluidizatio } \\
\text { with } \mathrm{N}_{2} \text { at } 900^{\circ} \mathrm{C}\end{array}$ & \multicolumn{2}{|c|}{ Minimum fluidization velocity } & 3.23 \\
\hline \multicolumn{4}{|c|}{ Proximate analysis [dry wt $\%$ ] } \\
\hline $\begin{array}{c}\text { Volatile matter } \\
23.6\end{array}$ & $\begin{array}{c}\text { Fixed carbon } \\
59.9\end{array}$ & & $\begin{array}{l}\text { Ash } \\
16.5\end{array}$ \\
\hline \multicolumn{4}{|c|}{ Ultimate analysis [dry wt \%] } \\
\hline $\mathrm{H}$ & $\mathrm{N}$ & $\mathrm{S}$ & $\mathrm{O}$ \\
\hline 67.4 & 1.3 & 0.2 & 10.6 \\
\hline
\end{tabular}

Table 2. Scope of experiments

\begin{tabular}{llc}
$\begin{array}{l}\text { Thermogravimetric analysis } \\
\text { Reaction temperature } \\
\text { Superficial gas velocity }\end{array}$ & {$[\mathrm{K}]$} & 1150 to 1263 \\
$\quad$ & {$[\mathrm{~m} / \mathrm{s}]$} & 0.17 \\
$\quad \begin{array}{l}\text { at reaction temperature } \\
\text { Steam concentration }\end{array}$ & {$[\mathrm{kPa}]$} & 5.0 to 30.5 \\
$\begin{array}{l}\text { Hydrogen concentration } \\
\text { Carbon monoxide concentration }\end{array}$ & {$[\mathrm{kPa}]$} & 0 to 19.0 \\
$\quad[\mathrm{kPa}]$ & 0 to 20.6 \\
$\begin{array}{l}\text { Fluidized-bed gasification } \\
\text { Bed temperature }\end{array}$ & {$[\mathrm{K}]$} & 1096 to 1311 \\
$\begin{array}{l}\text { Superficial gas velocity } \\
\text { at reaction temperature }\end{array}$ & {$[\mathrm{m} / \mathrm{s}]$} & 0.152 \\
$\begin{array}{l}\text { Steam concentration } \\
\text { Char feed rate }\end{array}$ & {$[\mathrm{kPa}]$} & 38.0 to 46.5 \\
& {$[\mathrm{~g} / \mathrm{s}]$} & 0.083 to 0.100 \\
\hline
\end{tabular}

change was recorded continuously.

The scope of the experiments is shown in Table 2. The concentration change of reactant gas within the reactor was less than 2 percent during this study. Thus the concentration of the reactant gas could be assumed constant around char particles.

\subsection{Results obtained by thermogravimetric analysis}

The weight decrease of sample due to drying and carbonization was measured in the nitrogen atmosphere. After steam and nitrogen mixture was introduced, the weight change due to gasification was recorded. The carbon conversion, $X$, due to the gasification was defined as

$$
X=\frac{W-W_{\text {ash }}}{W_{0}-W_{\text {ash }}}
$$

where $W_{0}$ is the weight of char measured after the completion of carbonization and the weight of ash, $W_{\text {ash }}$, is determined after incinerating the residual carbon of samples by introducing air into the reactor. Thus the denominator of Eq. (1) was assumed to be the total carbon content which is gasified.

Effects of sample weight and size on the observed rate which might be caused by mass transfer resistance around or within sample particles were investigated. The conversion-versus-time curves were not affected by weight and size of samples, when the weight was less than $100 \mathrm{mg}$ and the particle size 


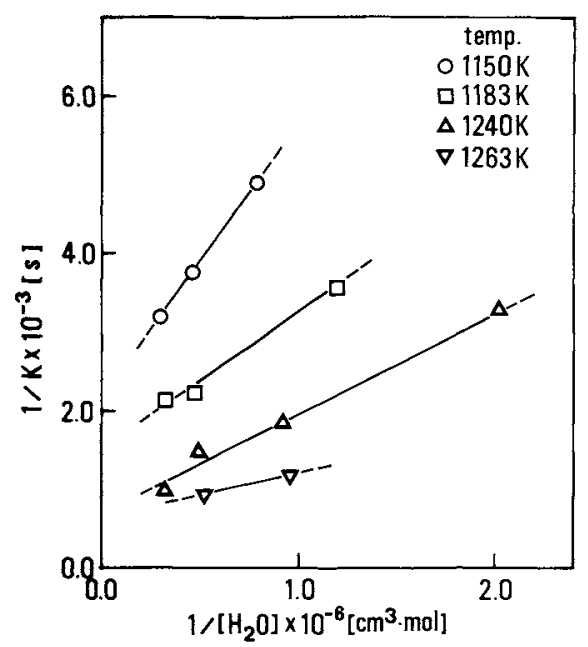

Fig. 1. Linearized plot of rate data at $50 \%$ carbon conversion - effect of steam.

smaller than $710 \mu \mathrm{m}$.

The derivatives of time-conversion curves are not entirely proportional to the unreacted carbon. Since one of our objectives in the present study was to examine whether or not the thermogravimetrically obtained kinetics could be used for analyzing the gasification performance in the fluidized bed, the kinetic constants were obtained at about the same solid conversion level that was observed in the continuous fluidized-bed gasification (described in the latter part of this paper). The rate constants used for this investigation were obtained by approximating by exponential function the middle part of the conversion versus time curve, where the carbon conversion level approximately corresponded to 0.50 and where the first-order kinetics with respect to carbon conversion, $X$, could be assumed. The effects caused by the reactant and the product on the rate were included in the following equation, where instantaneous adsorption equilibrium was assumed.

$$
\begin{aligned}
\frac{\mathrm{d} X}{\mathrm{~d} t} & =K(1-X) \\
& =\frac{k_{1}\left[\mathrm{H}_{2} \mathrm{O}\right]}{1+k_{2}\left[\mathrm{H}_{2} \mathrm{O}\right]+k_{3}\left[\mathrm{H}_{2}\right]+k_{4}[\mathrm{CO}]}(1-X)
\end{aligned}
$$

The rate parameters in Eq. (2) are dependent on the level of carbon conversion. However, the values of the parameters were determined at $X=0.50$, which is approximately the same level as the average carbon conversion obtained in the fluidized-bed experiments. The effect of the carbon conversion level used for the determination of the rate constants is discussed elsewhere. ${ }^{8)}$

The rate constants were measured under various steam concentrations by ignoring the effects of the hydrogen and carbon monoxide produced. Figure 1 shows a reciprocal plot of the reaction rates and

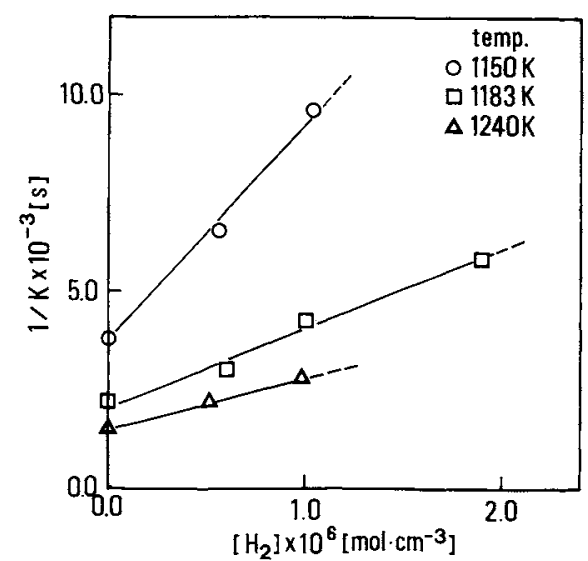

Fig. 2. Linearized plot of rate data at $50 \%$ carbon conversion -effect of hydrogen.

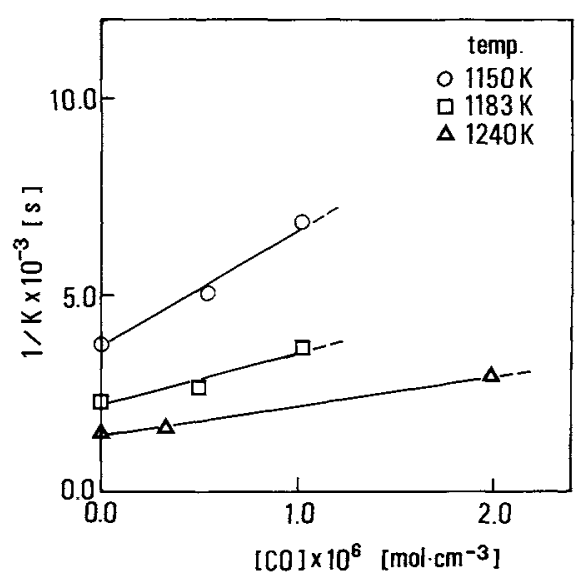

Fig. 3. Linearized plot of rate data at $50 \%$ carbon conversion-effect of carbon monoxide.

steam concentrations. Under the experimental conditions employed, a good linear relationship between the reciprocals of reaction rates and those of steam concentrations was obtained. The rate constant and the adsorption equilibrium constant of steam were determined from the slope and intercept at the ordinate. A series of experiments was also conducted to evaluate the effects of hydrogen on the rate by keeping the concentration of steam constant but changing the concentration of hydrogen. Since the above two parameters were previously determined, the adsorption equilibrium constant of hydrogen could be evaluated by plotting the reciprocal of the rate against concentration of hydrogen in Fig. 2. Similar experiments were also carried out to determine the equilibrium constant of carbon monoxide. Figure 3 represents the reciprocal rate plotted against concentration of carbon monoxide. The temperature effects on the rate constants are plotted in Fig. 4. From these figures, the rate parameters were determined at the level of carbon conversion of 0.50 as 


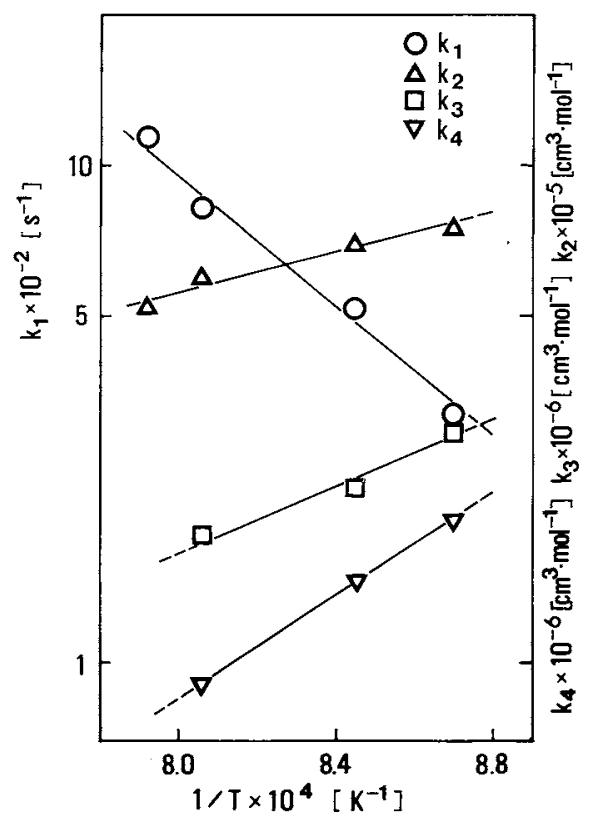

Fig. 4. Arrhenius plot of reaction rate constants at $50 \%$ carbon conversion.

$$
\begin{aligned}
& k_{1}=2.39 \times 10^{8} \exp (-129000 / R T) \\
& k_{2}=3.16 \times 10^{4} \exp (30100 / R T) \\
& k_{3}=5.36 \times 10^{3} \exp (59800 / R T) \\
& k_{4}=82.5 \times \exp (96100 / R T)
\end{aligned}
$$

Von Fredersdorff and Elliott ${ }^{16)}$ showed that the reactivity of carbon is significantly affected by the type of carbon. The activation energy previously obtained for the constant, $k_{1}$, ranged from 55 to $260 \mathrm{~kJ} / \mathrm{mol}$. The value of the activation energy obtained by the present investigation was $129 \mathrm{~kJ} / \mathrm{mol}$.

\section{Fluidized Bed Gasification}

\subsection{Experimental}

Apparatus Steam, generated by evaporating deionized water in flowing nitrogen, was used as the gasifying agent. The fluidized-bed gasification system used for this investigation is shown in the previous paper. ${ }^{8)}$ The system was operated at atmospheric pressure. The main parts of the reactor consist of the solid-feed system and overflow collection units, cyclones, gas-feed system, electric furnace, and fluidized-bed reactor.

The reactor employed was made of stainless steel and the inner diameter was $79 \mathrm{~mm}$. The effective bed height was kept at $196 \mathrm{~mm}$ by discharging the solids through the overflow pipe. The lower part of the vessel was packed with ceramic balls $(8 \mathrm{~mm}$ in diameter) and used for preheating. A multi-orifice plate was used as a gas distributor. Since the quality of fluidization is strongly influenced by the type of gas distributor used, the multi-orifice plate is designed so that sufficient pressure drop to achieve homogeneous fluidization can be realized. The observed pressure drop ranged from $6.4 \mathrm{kPa}$ to $9.3 \mathrm{kPa}$.

The reactor was heated to the desired reaction temperature by means of an external electric furnace. The bed temperature was measured by a sheathed chromel-alumel thermocouple $(6 \mathrm{~mm}$ o.d.) located in the fluidized zone, and the outside wall temperature was detected by a sheathed chromel-alumel thermocouple $(5 \mathrm{~mm}$ o.d.) and controlled by a conventional ON-OFF controller.

The char was fed at $23 \mathrm{~mm}$ above the gas distributor, through a stainless tube $(10 \mathrm{~mm}$ i.d.) from a hopper by a vibration feeder made by Shinko Electric Works. A continuous feed of solids even at a feed rate of $0.10 \mathrm{~g} / \mathrm{s}$ or less could be realized. During the runs, nitrogen was supplied to the hopper as a carrier gas.

Entrained particles from the reactor were separated from the gas by two serial cyclones. Overflowing solids were collected in a tight catch-pot. Both types of particles were periodically sampled during the runs. Weight decrease of the solids after incineration was measured by a conventional balance and then the carbon conversions were calculated.

The gases produced were periodically withdrawn into a glass vessel $(300 \mathrm{ml}$ in volume) and were analyzed by Shimadzu gas chromatographs (type 6A and type 3BT), which had respectively column packings of Porapack QS and MS 5A. $\mathrm{H}_{2}, \mathrm{CO}, \mathrm{CH}_{4}$ and $\mathrm{N}_{2}$ were analysed by MS $5 \mathrm{~A}$ and $\mathrm{CO}_{2}$ was analysed by Porapack QS. Unconverted steam collected by use of a condenser attached to an ice trap was measured intermittently.

Procedure The reactor, initially packed with char, was heated to the desired temperature at a rate of about $10 \mathrm{~K} / \mathrm{min}$ in a nitrogen atmosphere. The superficial velocity of nitrogen through the gas distributor and solid feed tube was totally adjusted at $152 \mathrm{~mm} / \mathrm{s}$ at the reaction temperature, which is the same as under the gasification condition. This gas velocity corresponds to 4.77 to 5.09 times the minimum fluidization velocity calculated by Wen and Yu's equation. ${ }^{17)}$ When the desired temperature was attained, a mixture of steam and $\mathrm{N}_{2}$ was introduced and the feeding of char was initiated. The results of gas analysis showed that about $3 \sim 4 \mathrm{~h}$ were required to approach steady-state operation. The steady state was maintained for about $1 \mathrm{~h}$, where several sets of gas and solid samples were taken and analyzed.

\subsection{Experimental results}

Pyrolysis in nitrogen atmosphere Since the coal char employed contains a small amount of volatile matter, pyrolysis also took place during the gasification run. The experiments were conducted in a nitrogen atmosphere to evaluate the amount of gases produced by pyrolysis. The flow rate of nitrogen was the same as the total gas flow rate under the gasification condition 


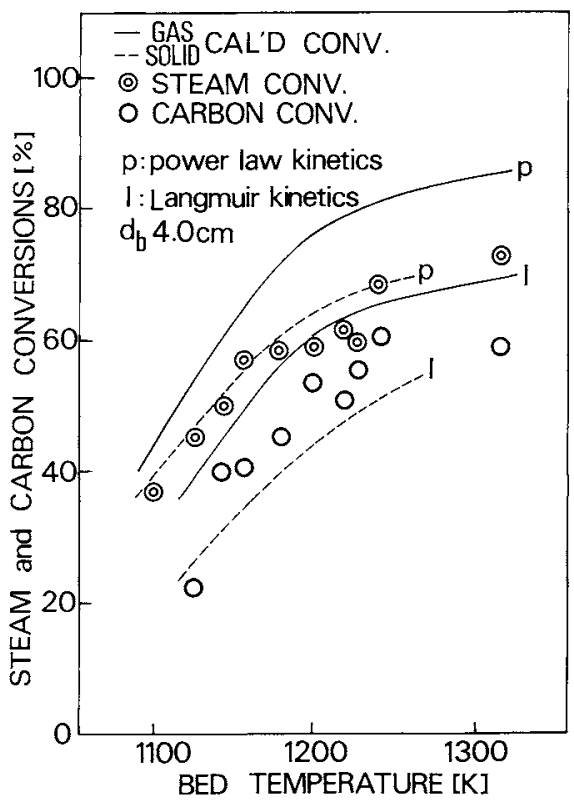

Fig. 5. Conversions of steam and carbon.

and the coal char feed rate was adjusted to the same as that in the gasification run. Carbon monoxide and hydrogen were the main products and no carbon dioxide was detected. The yield of the gas produced by pyrolysis per amount of feed char was reported elsewhere. ${ }^{9)}$ The solid residue from pyrolysis amounted approximately to the value of the fixed carbon and ash in the proximate analysis of the employed char. Thus the residual solids were assumed to consist of carbon and ash in the present analysis.

Gasification experiments The production rate of hydrogen and carbon monoxide was obtained by analyzing the outlet gas from the gasifier. As mentioned above, the pyrolysis reaction produced a certain amount of hydrogen and carbon monoxide. The present analysis assumed that pyrolysis took place instantaneously, to be followed by gasification. Thus the gasification reaction and pyrolysis were assumed to take place independently and the conversion of steam was defined as

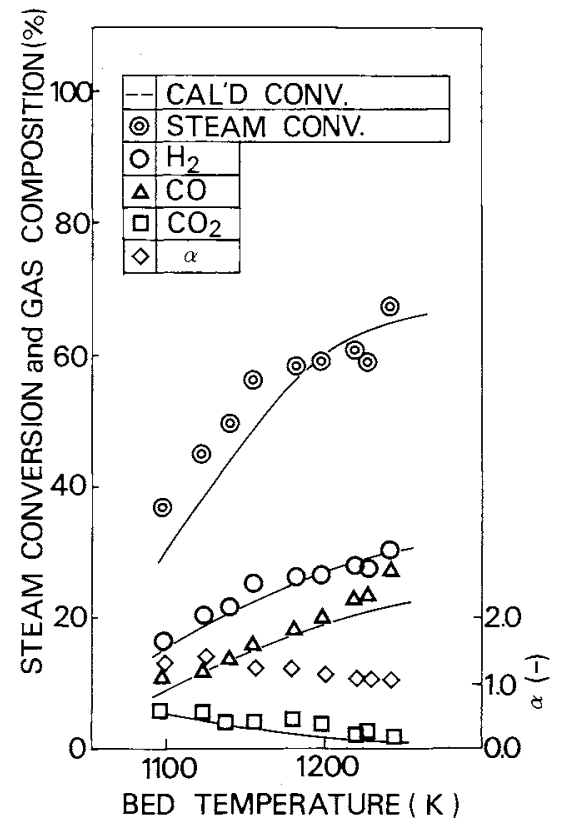

Fig. 6. Composition of gas produced and product distribution coefficient.

Experimentally obtained steam and carbon conversions against bed temperatures are shown in Fig. 5. The product distributions are shown in Fig. 6.

\section{Mathematical Model for the Fluidized Bed Gasi- fier}

The conversions of steam and carbon were evaluated by use of the thermogravimetrically obtained kinetic equation and the modified bubbling-bed model, where all the hydrodynamic properties can be evaluated by functions of the effective bubble diameter. Chang et al. $^{4)}$ reported the ambiguity of bubble size measurement. Thus the bubble size was used as an adjustable parameter in this investigation. The measurement of bubble size was also conducted and details were reported elsewhere. ${ }^{8)}$ Table 3 summarizes the basic equations of the bubbling-bed model.

The extent of the reaction in the gas phase must be stoichiometrically equivalent to the conversion of

$$
X_{\mathrm{H}_{2} \mathrm{O}}=\frac{\left(\mathrm{H}_{2} \text { production in gasification experiments }\right)-\left(\mathrm{H}_{2} \text { production in pyrolysis experiments }\right)}{\text { feed rate of } \mathrm{H}_{2} \mathrm{O}}
$$

Also, carbon conversion was defined as

$$
X_{B}=1-\left\{\frac{\left(\begin{array}{c}
\text { discharge rate } \\
\text { of char }
\end{array}\right)-\left(\begin{array}{c}
\text { discharge rate } \\
\text { of ash }
\end{array}\right)}{\left(\begin{array}{c}
\text { feed rate } \\
\text { of char }
\end{array}\right)-\left(\begin{array}{c}
\text { rate of volatile loss } \\
\text { by pyrolysis }
\end{array}\right)-\left(\begin{array}{c}
\text { feed rate } \\
\text { of ash }
\end{array}\right)}\right\}
$$

solids. However, the bubble fraction of the bed in the conventional bubbling-bed model was expressed by the following equation, which ignores the effect caused by the gas flowing through the emulsion phase at the minimum fluidization velocity on the total conversion of the gas leaving the bed.

$$
\delta=\frac{u_{0}-u_{m f}}{u_{b}}
$$

Therefore, Eq. (6), which assumes that all the gases 
Table 3. Basic equations for the hydrodynamic parameters of the modified bubbling-bed model and the mass balance equations

Minimum fluidization velocity

Bubble rise velocity with respect to emulsion phase

Bubble rise velocity

Bubble volume fraction

Volume fraction of solid in bubbles

Volume fraction of solid in cloud-wake

Weight fraction of solid in bubbles

Weight fraction of solid in cloud-wake

Weight fraction of solid in emulsion

Volume fraction of solid in emulsion

Interchange coefficient between bubble and cloud-wake phases

Interchange coefficient between cloud-wake and emulsion phases

$$
\begin{aligned}
& u_{m f}=\frac{d_{p}^{2}\left(\rho_{s}-\rho_{g}\right) g}{1650 \mu} \\
& u_{b r}=0.711\left(g d_{b}\right)^{1 / 2} \\
& u_{b}=u_{0}-u_{m f}+u_{b r} \\
& \delta=u_{0} / u_{b} \\
& \gamma_{b}=0.005 \\
& \gamma_{c}=\left(1-\varepsilon_{m f}\right)\left(-\frac{3 u_{m f} / \varepsilon_{m f}}{u_{b r}-u_{m f} / \varepsilon_{m f}}+\frac{V_{w}}{V_{b}}\right) \\
& m_{b}=\frac{\delta \gamma_{b}}{(1-\delta)\left(1-\varepsilon_{m j}\right)} \\
& m_{c}=\frac{\delta \gamma_{c}}{(1-\delta)\left(1-\varepsilon_{m f}\right)} \\
& m_{e}=1-m_{b}-m_{c} \\
& \gamma_{e}=\frac{(1-\delta)\left(1-\varepsilon_{m f}\right)}{\delta} m_{e} \\
& K_{b c}=4.5\left(\frac{u_{m f}}{d_{b}}\right)+5.85\left(\frac{D^{1 / 2} g^{1 / 4}}{d_{b}^{5 / 4}}\right) \\
& K_{c e}=6.78\left(\frac{\varepsilon_{m f} D u_{b}}{d_{b}^{3}}\right)^{1 / 2}
\end{aligned}
$$

Mass balance equaitions

Reactant gas rate equation:

$$
\begin{aligned}
& r_{A}=-\frac{\mathrm{d}\left[\mathrm{H}_{2} \mathrm{O}\right]}{\mathrm{d} t}=\frac{k_{1}\left[\mathrm{H}_{2} \mathrm{O}\right]}{1+k_{2}\left[\mathrm{H}_{2} \mathrm{O}\right]+k_{3}\left[\mathrm{H}_{2}\right]+k_{4}[\mathrm{CO}]} \frac{\rho_{s} F_{c}}{M_{B}}(1-X) \alpha \\
& r_{B}=\frac{\mathrm{d}\left[\mathrm{H}_{2}\right]}{\mathrm{d} t}=-r_{A} \\
& r_{C}=\frac{\mathrm{d}[\mathrm{CO}]}{\mathrm{dt}}=-r_{A} \cdot \frac{(2-\alpha)}{\alpha} \\
& r_{D}=\frac{\mathrm{d}\left[\mathrm{CO}_{2}\right]}{\mathrm{d} t}=-r_{A} \cdot \frac{(\alpha-1)}{\alpha} \\
& -u_{b} \frac{\mathrm{d} C_{i, b}}{\mathrm{~d} h}=\gamma_{b} r_{i, b}+K_{b c, i}\left(C_{i, b}-C_{i, c}\right) \\
& K_{b c, i}\left(C_{i, b}-C_{i, c}\right)=\gamma_{c} r_{i, c}+K_{c e, i}\left(C_{i, c}-C_{i, e}\right) \\
& K_{c e, i}\left(C_{i, c}-C_{i, e}\right)=\gamma_{e} r_{i, e} \\
& i=A, B, C, D \\
& A=\mathrm{H}_{2} \mathrm{O}, \quad B=\mathrm{H}_{2}, \quad C=\mathrm{CO}, \quad D=\mathrm{CO}_{2} \\
& \frac{\mathrm{d} X}{\mathrm{~d} t}=m_{b} \frac{k_{1}\left[\mathrm{H}_{2} \mathrm{O}\right]_{b}}{1+k_{2}\left[\mathrm{H}_{2} \mathrm{O}\right]_{b}+k_{3}\left[\mathrm{H}_{2}\right]_{b}+k_{4}[\mathrm{CO}]_{b}}-(1-X) \\
& +m_{c} \frac{k_{1}\left[\mathrm{H}_{2} \mathrm{O}\right]_{c}}{1+k_{2}\left[\mathrm{H}_{2} \mathrm{O}\right]_{c}+k_{3}\left[\mathrm{H}_{2}\right]_{c}+k_{4}[\mathrm{CO}]_{c}}(1-X) \\
& +m_{e} \frac{k_{1}\left[\mathrm{H}_{2} \mathrm{O}\right]_{e}}{1+k_{2}\left[\mathrm{H}_{2} \mathrm{O}\right]_{e}+k_{3}\left[\mathrm{H}_{2}\right]_{e}+k_{4}[\mathrm{CO}]_{e}}(1-X)
\end{aligned}
$$

travel through the bed only as bubbles, was used. Thus the bubble volume fraction was defined as Eq. (6).

Equation (2) for the carbon conversion was ob- tained by thermogravimetric analysis.

In the steam gasification system, the following two reactions could be assumed to take place. 


$$
\begin{aligned}
& \mathrm{C}+\mathrm{H}_{2} \mathrm{O} \rightarrow \mathrm{CO}+\mathrm{H}_{2} \\
& \mathrm{CO}+\mathrm{H}_{2} \mathrm{O} \rightarrow \mathrm{CO}_{2}+\mathrm{H}_{2}
\end{aligned}
$$

Equation (21) can be replaced by the following Eq. (22).

$$
\mathrm{C}+2 \mathrm{H}_{2} \mathrm{O} \rightarrow \mathrm{CO}_{2}+2 \mathrm{H}_{2}
$$

Equations (20) and (22) can be combined into

$$
\mathrm{C}+\alpha \mathrm{H}_{2} \mathrm{O} \rightarrow(2-\alpha) \mathrm{CO}+(\alpha-1) \mathrm{CO}_{2}+\alpha \mathrm{H}_{2}
$$

Where $(2-\alpha) / \alpha$ represents the fraction of the steam consumed by the reaction path (20) and $2(\alpha-1) / \alpha$ represents the fraction of the steam consumed by the reaction path (22). The products distribution coefficient, $\alpha$, was experimentally determined from Fig. 6 by subtracting the gas produced by pyrolysis, and the value of $\alpha$ is shown in Fig. 6. This rate equation can be rewritten for the gas phase.

$$
\begin{aligned}
& -\frac{\mathrm{d}\left[\mathrm{H}_{2} \mathrm{O}\right]}{\mathrm{d} t}=\frac{\mathrm{d} X}{\mathrm{~d} t} \frac{\rho_{s} F_{c}}{M_{B}} \alpha \\
& =\frac{k_{1}\left[\mathrm{H}_{2} \mathrm{O}\right]}{1+k_{2}\left[\mathrm{H}_{2} \mathrm{O}\right]+k_{3}\left[\mathrm{H}_{2}\right]+k_{4}[\mathrm{CO}]} \frac{\rho_{\mathrm{s}} F_{c}}{M_{B}} \alpha(1-X)
\end{aligned}
$$

Steady-state conversions of gas and solids could not be analytically obtained for the nonlinear rate equation expressed by Eq. (14) by the conventional bubbling-bed model. ${ }^{7}$ ) Therefore, a numerical calculation procedure which follows the transient change of the solid conversion level and corresponding gasphase concentration was developed in the previous study. ${ }^{8)}$ The same procedure was applied to the present analysis. The parameters used are summarized in Table 4. Another series of calculations was carried out by using the following power law kinetics, obtained previously by the present authors. ${ }^{9)}$

$$
\begin{aligned}
\frac{\mathrm{d} X}{\mathrm{~d} t} & =k_{p}\left[\mathrm{H}_{2} \mathrm{O}\right]^{0.45}(1-X) \\
k_{p} & =3.98 \times 10^{5} \exp (-146500 / R T)
\end{aligned}
$$

Both results are illustrated in Fig. 5.

\section{Comparison of Experimental Results with Pre- dicted Results}

The numerically obtained conversions of both steam and carbon could generally explain the experimentally observed values. The effective bubble diameter, which gives the best fit between the experimental results and the calculation results, is reduced by utilizing a Langmuir-type equation which assumes instantaneous adsorption equilibrium. Furthermore, the effective bubble diameter agreed well with the diameter measured by use of an electro-resistivity probe in our previous study. ${ }^{8)}$ This effective bubble diameter appears to underestimate the conversion of
Table 4. Values of parameters for the bubbling-bed model and computational parameters

\begin{tabular}{llc}
\hline Bubble diameter & {$[\mathrm{cm}]$} & 4.0 \\
Void fraction of bed at minimum & & \\
$\quad$ fluidization condition & {$[-]$} & 0.5 \\
Ratio of wake volume to bubble volume & {$[-]$} & 0.25 \\
Time increment & {$[\mathrm{s}]$} & 60.0 \\
Number of compartments & {$[-]$} & 100 \\
\hline
\end{tabular}

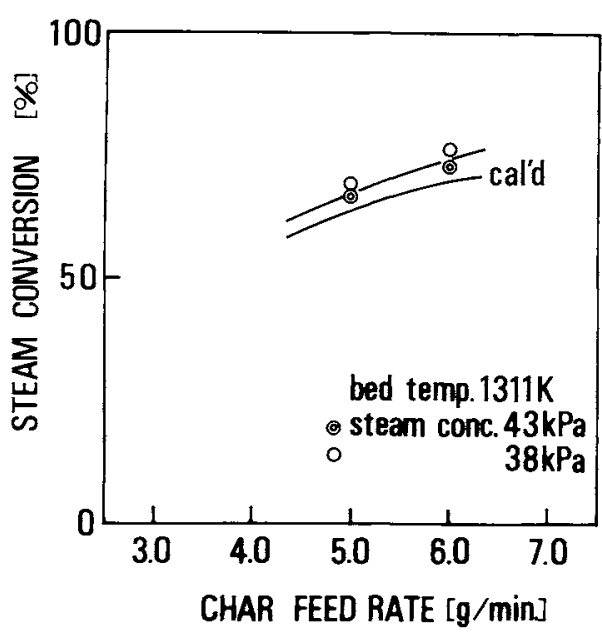

Fig. 7. Steam conversion at $1311 \mathrm{~K}$-effect of char feed rate.

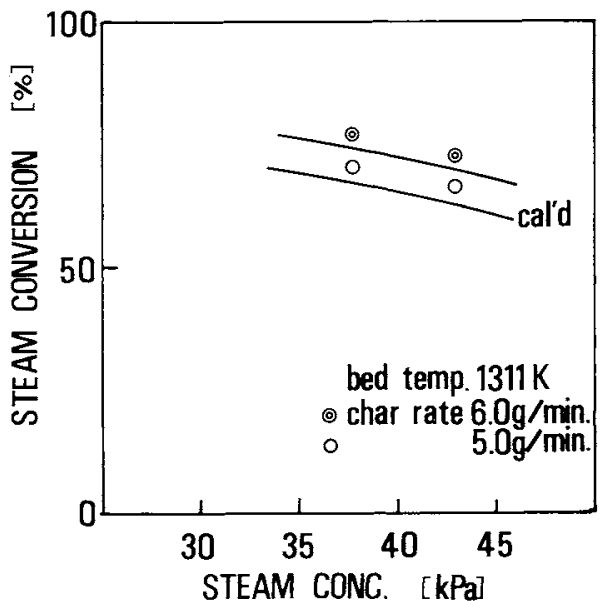

Fig. 8. Steam conversion at $1311 \mathrm{~K}$ - effect of steam concentration.

solid in Fig. 5. Since preliminary experiments by thermogravimetric apparatus showed that the steam gasification rate of the char used for the present study was at least three times larger than the rate of carbon dioxide gasification, the gasification by carbon dioxide produced in situ was ignored in the present calculation. The experimentally observed conversion of solids is slightly higher than the calculated values. This discrepancy can be attributed to ignoring secondary char gasification by carbon dioxide which was produced by steam gasification of char. It was assumed that the pyrolysis reaction and the steam 
gasification took place independently. Thus the gas composition of the fluidized bed was calculated by superposing the calculated results of the steam gasification on the experimental results of the pyrolysis conducted in a nitrogen atmosphere by use of the continuous fluidized bed. ${ }^{9)}$ The calculated results shown in Fig. 6 agreed well with the experimentally observed composition of the outlet gas. Squires ${ }^{12)}$ suggested that the circulative motion of char particles from the oxidizing zone to the reducing zone of the bed and vice versa might increase the gasification rate and this effect might be enhanced at elevated temperature. An additional series of experiments was conducted to investigate the above effects of temperature on the validity of the model. The results obtained, together with the calculated results, are shown in Figs. 7 and 8. As mentioned above, the rate equation (2) and a modified bubbling-bed model which employs the bubble diameter observed at the middle height of the bed explained the experimental results of the fluidized bed gasification at temperatures ranging from 1096.0 to $1236.7 \mathrm{~K}$. Even at $1311 \mathrm{~K}$, the kinetic expression (2), which assumes instantaneous adsorption equilibrium of $\mathrm{H}_{2} \mathrm{O}, \mathrm{CO}$, and $\mathrm{CO}_{2}$, proved to be sound in analyzing the fluidized bed gasification. ${ }^{13)}$

\section{Conclusion}

Continuous gasification of coal-derived char with steam was carried out in a fluidized bed over a temperature range of $1096 \mathrm{~K}$ to $1311 \mathrm{~K}$ at atmospheric pressure. The conversion of steam and the composition of the gas produced were analyzed by assuming that pyrolysis reaction and steam gasification were simultaneously and independently taking place in the reactor. The amount of gas produced by pyrolysis was measured separately by introducing nitrogen into the reactor. The conversions of steam and char were calculated by a modified bubbling-bed model $^{8)}$ and a kinetic equation obtained by conventional thermogravimetric analysis. Hydrodynamic constants were estimated by the conventional procedure. Here care was taken for the gas flow through the emulsion phase so that the consumption of solids can be stoichiometrically consistent with that of the gas phase. The predicted conversion of gas and solids could reasonably explain the experimental results.

\section{Acknowledgment}

The author (D.K.) wishes to express his thanks to Grants in Aid for Energy Research (56040005, 57040006 and 58040009) of the Ministry of Education, Science and Culture, Japan. The know-how provided by Professor Kasaoka, Okayama University, concerning thermogravimetric measurement is greatly appreciated.

\section{Nomenclature}

$[\mathrm{CO}]=$ concentration of carbon monoxide $\left[\mathrm{mol} \mathrm{cm}{ }^{-3}\right]$ $\left[\mathrm{CO}_{2}\right]=$ concentration of carbon dioxide $\left[\mathrm{mol} \mathrm{cm}{ }^{-3}\right]$

\begin{tabular}{|c|c|c|c|}
\hline$d_{b}$ & $=$ & bubble diameter & {$[\mathrm{cm}]$} \\
\hline$F_{c}$ & $=$ & weight fraction of carbon in char particle & {$[-]$} \\
\hline$\left[\mathrm{H}_{2}\right]$ & & concentration of hydrogen & {$\left[\mathrm{mol} \mathrm{cm}^{-3}\right]$} \\
\hline$\left[\mathrm{H}_{2} \mathrm{O}\right]$ & & concentration of steam & {$\left[\mathrm{mol} \mathrm{cm}^{-3}\right]$} \\
\hline$k_{\mathrm{t}}$ & $=$ & rate constant for $\mathrm{C}-\mathrm{H}_{2} \mathrm{O}$ reaction & \multirow{2}{*}{$\begin{array}{r}{\left[\mathrm{s}^{-1}\right]} \\
{\left[\mathrm{cm}^{3} \mathrm{~mol}^{-1}\right]}\end{array}$} \\
\hline$k_{2}$ & & equilibrium constant & \\
\hline$k_{3}$ & & equilibrium constant & {$\left[\mathrm{cm}^{3} \mathrm{~mol}^{-1}\right]$} \\
\hline$k_{4}$ & & equilibrium constant & {$\left[\mathrm{cm}^{3} \mathrm{~mol}^{-1}\right]$} \\
\hline$k_{p}$ & \multicolumn{3}{|c|}{$\begin{array}{l}=\text { rate constant in power law kinetics } \\
\qquad\left[\mathrm{s}^{-1}\left(\mathrm{~mol} / \mathrm{cm}^{3}\right)^{-0.45}\right]\end{array}$} \\
\hline$K_{b c}$ & & gas interchange coefficient & {$\left[\mathrm{s}^{-1}\right]$} \\
\hline$K_{c e}$ & & gas interchange coefficient & {$\left[\mathrm{s}^{-1}\right]$} \\
\hline$M_{B}$ & $=$ & molecular weight of carbon & $\left.\mathrm{nol}^{-1}\right]$ \\
\hline$m_{b}$ & & weight fraction of solids present in bubbles & \\
\hline$m_{c}$ & & $\begin{array}{l}\text { weight fraction of solids present in cloud- } \\
\text { wake }\end{array}$ & {$[-]$} \\
\hline$m_{e}$ & $=$ & weight fraction of solids present in emulsion & {$[-]$} \\
\hline$R$ & $=$ & gas constant & $\left.{ }^{1} \mathrm{~K}^{-1}\right]$ \\
\hline$r_{A}$ & & reaction rate of steam & $\left.{ }^{-3} s^{-1}\right]$ \\
\hline$T$ & & temperature & {$[\mathrm{K}]$} \\
\hline$u_{0}$ & & superficial gas velocity & $\left.\mathrm{m} \mathrm{s}^{-1}\right]$ \\
\hline$u_{b}$ & & bubble rise velocity & $\left.\mathrm{ms}^{-1}\right]$ \\
\hline$W$ & & weight of particle & [g] \\
\hline$W_{0}$ & & initial weight of particle & [g] \\
\hline$W_{\text {ash }}$ & & weight of ash & {$[\mathrm{g}]$} \\
\hline$X$ & $=$ & carbon conversion & {$[-]$} \\
\hline$X_{B}$ & $=$ & conversion of carbon leaving fluidized bed & {$[-]$} \\
\hline$X_{\mathrm{H}_{2} \mathrm{O}}$ & & conversion of steam & {$[-]$} \\
\hline$\alpha$ & & product distribution coefficient & {$[-]$} \\
\hline$\gamma_{b}$ & & volume fraction of solids in bubble phase & {$[-]$} \\
\hline$\gamma_{c}$ & & $\begin{array}{l}\text { volume fraction of solids in cloud-wake } \\
\text { phase }\end{array}$ & {$[-]$} \\
\hline$\gamma_{e}$ & $=$ & volume fraction of solids in emulsion phase & {$[-]$} \\
\hline$\delta$ & & bubble volume fraction & {$[-]$} \\
\hline$\rho_{s}$ & $=$ & particle density & $\left.\mathrm{cm}^{-3}\right]$ \\
\hline
\end{tabular}

$\langle$ Subscripts〉

$\begin{array}{ll}b & =\text { bubble phase } \\ c & =\text { cloud-wake phase } \\ e & =\text { emulsion phase }\end{array}$

\section{Literature Cited}

1) Bjerle, I., H. Eklund, M. Linne and O. Svensson: Ind. Eng. Chem., Process Des. Dev., 21, 141 (1982).

2) Bjerle, I., H. Eklund and O. Svensson: Ind. Eng. Chem., Process Des. Dev., 19, 345 (1980).

3) Barnham, A.: Fuel, 58, 285 (1979).

4) Chang, C. C., L. T. Fan and S. X. Rong: Can. J. Chem. Eng., 60, 272 (1982).

5) Dutta, S., C. Y. Wen and R. J. Belt: Ind. Eng. Chem., Process Des. Dev., 16, 20 (1977).

6) Fee, D. C.: Argonne National Laboratory Report, ANL/FE80-101, (1982).

7) Kunii, D. and O. Levenspiel: "Fluidization Engineering," John Wiley, New York (1969).

8) Matsui, I., T. Kojima, T. Furusawa and D. Kunii: submitted to Ind. Eng. Chem., Process Des. Dev.

9) Matsui, I., T. Kojima, T. Furusawa and D. Kunii: "Fluidization," p. 655, ed. by D. Kunii and R. Toei, A.I.Ch.E: (1984).

10) May, W. G., R. H. Mueller and S. B. Sweetser: Ind. Eng. Chem., 50, 1289 (1958).

11) Newby, A. W.: Proceedings of 6th International Conference on FBC, 803 (1980). 
12) Squires, A. M.: private communication.

13) Squires, A. M.: Trans. Inst. Chem. Engrs., 39, 3 (1961).

14) Takeda, S., J. Kawabata, M. Yumiyama, Y. Tazaki, S. Honma and S. Mori: Nenryokyokaishi, 59, 64 (1980).

15) Takeda, S., J. Kawabata, M. Yumitama, Y. Tazaki, S.
Honma and S. Mori: Nenryokyokaishi, 59, 323 (1980).

16) Von Fredersdorff, C. G. and T. S. Elliott: "Chemistry of Coal Utilization," Supplementary Volume, John Wiley, New York (1963).

17) Wen, C. Y. and Y. H. Yu: $A I C h E J ., 12,610$ (1960).

\title{
BEHAVIOR OF FLUIDIZED BEDS OF SMALL PARTICLES AT ELEVATED TEMPERATURES
}

\author{
TAKAMI KAI AND SHINTARO FURUSAKI \\ Department of Chemical Engineering, University of Tokyo, Tokyo 113
}

\author{
Key Words: Fluidization, Fluidity, Elevated Temperature, Bubble Frequency, Bubble Size, Pressure \\ Fluctuations, Electrostatic Force
}

\begin{abstract}
Pressure fluctuations and bubble frequency in fluidized beds were measured at several stages of temperature ranging from $280 \mathrm{~K}$ to $640 \mathrm{~K}$. Four types of powders belonging to group A of Geldart's classification were used. The quality of fluidization at various temperatures was evaluated by a uniformity index based on pressure fluctuations and by bubble size obtained from bubble frequency. The reduction both in the deviation of amplitude of pressure fluctuations and in bubble size showed that the quality of fluidization improved with increasing temperature. However, at room temperature, beds of dry particles were affected by electrostatic phenomena and thus the fluidity was decreased. The influence of the electrification decreased at elevated temperature, or at room temperature when the particles held water in the pores.
\end{abstract}

\section{Introduction}

Studies of fluidized beds have generally been carried out by using air under ambient conditions. Industrial processes are, however, operated at elevated temperatures. Geldart et al. ${ }^{6}$ have suggested that the fluidization behavior of powders in the cold model using air should be treated with caution in scaling-up with other gases and operating conditions.

Most of the studies at elevated temperatures have been concerned with the effect of bed temperature on minimum fluidizing velocity. Several studies have been carried out on behavior of bubbling or turbulent fluidization. Otake et al. ${ }^{14)}$ have measured bubble frequency at various temperatures. They found that bubble frequency increased with bed temperature. Similar results were obtained by Mii et al ${ }^{97}$ Tone et al. ${ }^{18)}$ have proposed a correlation between bubble diameter and bed temperature by measuring bubble frequency. Yoshida et al. ${ }^{21)}$ have measured bubble size with changing temperature in two-dimensional beds. Geldart et al. ${ }^{5}$ have estimated bubble size from eruption diameter. According to their results the bubble size decreased with increasing temperature.

Received May 11, 1984. Correspondence concerning this article should be addressed to S. Furusaki. T. Kai is now at Dept. of Chem. Eng., Kagoshima Univ., Kagoshima 890.
The decrease in bubble size seems to indicate improvement in the quality of fluidization with increasing temperature.

The fluidity can also be judged from pressure fluctuations. Svoboda et al. ${ }^{17)}$ have studied the dependence of frequency spectrum, dominant frequency, and mean amplitude of pressure fluctuations on temperature. The mean amplitude decreased and the frequency increased with increasing temperature.

The average particle size employed in the studies referred to above was limited to that larger than $70 \mu \mathrm{m}$. Fluidized beds of small particles $\left(d_{p}=50\right.$ $70 \mu \mathrm{m})$ at elevated temperature have not sufficiently been studied, although the bed behavior with small particles differs from that with large particles even at ambient temperature. Thus the purpose of the present study is to find the effect of temperature both on bubble size and on pressure fluctuations in a fluidized bed of small particles.

\section{Experimental Apparatus and Procedure}

\subsection{Particles used}

Four types of powders of different properties were used. Their physical properties are summarized in Table 1. Only the silica particles are not classified as $\mathrm{A}^{\prime}$ group of Ikeda's criterion ${ }^{7)}$ for good fluidization, 